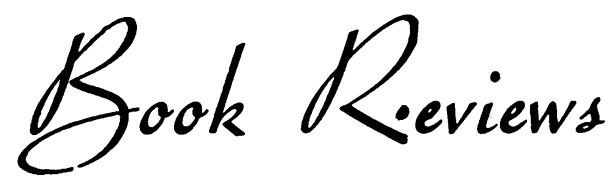

\section{CARCINOMA OF THE LUNG}

Edited by J. R. Bignall, M.D., M.R.C.P. Pp. xii +298 , illustrated. Edinburgh: E. \& S. Livingstone Ltd. 1958. $55 \mathrm{~s}$.

This monograph is the first of a series to be published under the general editorship of Professor D. W. Smithers on Neoplastic Disease at various sites.

It is divided into five sections, which deal with the mortality, aetiology, pathology, course and treatment of lung cancer, and the contributors to each section cover the subject very fully. Many of the opinions expressed are backed by statistical evidence derived from the numerous surveys that have now been carried out in relation to the various aspects of the disease: however, statistics are nicely balanced with the text and a readable book has resulted.

It represents an important British contribution to this very pressing subject and it can be strongly recommended.

L.L.B.

\section{COMPARATIVE ASPECTS OF HAEMOLYTIC DISEASE OF THE NEWBORN}

By G. Fulton Roberts, M.A., M.D. Pp. 199. London: William Heinemann Ltd. 1957. 17s. 6d.

The author, who is lecturer in pathology at Cambridge University, is already known well in this field from his book on the Rhesus factor which appeared ro years ago.

Since the first case of hydrops and haemolytic disease of the newborn has been described in 1609 , an immense amount of knowledge about it has accumulated, particularly during the last few years. The historical, haematological, clinical and histological aspects of the disease in man are discussed, as it occurs in man, horse, mule, pig, guinea-pig, rat, dog and rabbit. Prophylactic, therapeutic and immunological management is outlined. In the appendix the author's historical scholarship is shown to full advantage, and his reading has been truly catholic as judged by his list of references.

One can well imagine that the book has been written for pleasure and it certainly provides pleasure for the reader.

E.N.

\section{ANTIBIOTICS ANNUAL, 1957-58}

Edited by H. Welch, Ph.D., and F. MartiIBAÑEZ, M.D. Pp. xvii + 1070, with diagrams. New York: Interscience Publishers, Inc. 1958. 40s.

This report on the Fifth Annual Symposium on Antibiotics provides with the previous volumes a fund of information on these drugs not otherwise easily available. It should, therefore, find a place on all medical library shelves. The papers included have been prepared to fit into the time allocated in a scientific meeting, but more detailed information can often be traced easily from their lists of references and they serve as a key to the literature in their respective fields.

Antibiotic research at present is concentrating on finding good antifungal agents. Papers on the uses of novobiocin, nystatin and amphotericin against these are prominent. The use of seromycin (cycloserine) in tuberculous patients when other forms of therapy have failed and the effects of a combination of antibiotics with gamma globulin are among the important series of reports.

Among items of general interest are the lecture by Jawetz, the survey of antibiotic reactions and the panel discussion on the prophylaxis of rheumatic fever. Hardly anyone engaged in medicine or clinical pathology and bacteriology can afford not to work through the index of this volume for items of special interest.

\section{W.H.H.}

\section{CLINICAL OBSTETRICS AND GYNAECOLOGY \\ Volume r, Number I}

Edited by Curtis J. Lund, M.D., and Allan C. Barnes, M.D. Pp. 288, illustrated. New York: Paul B. Hoeber, Inc. 1958.

This is an original compromise between a fullscale textbook of obstetrics and gynaecology and an ordinary journal with original papers.

Every three months or so, a well-bound book of some 250 pages will appear, to be bought on a subscription basis.

In each volume, one or, perhaps, two topics are being treated. In the first volume, the subject of this review, the two topics are: 
(I) Management of Endocrine Problems in Obstetrics and Gynaecology, and

(2) Medical Problems in Pregnancy.

For each topic there is an editor, who presumably co-ordinates the work of the dozen contributors, and certainly in this first volume the editing has been most skilful in avoiding overlapping.

I think the outstanding contributions in the Endocrine Section are the papers on Diabetes in Pregnancy and on the Adrenogenital Syndrome.

In the Medical Section, the paper on Anaemia in Pregnancy and the paper on Pregnancy in Diabetes with Vascular Complications are well informed and most helpful in the actual investigation and treatment of patients. They are both most authoritative.

The books are certainly not for undergraduate students, but for the postgraduate they will, within the next year and a half, provide a feast of information presented under the editorships of some of the best known names in American Obstetrics and Gynaecology. How digestible this feast will be, remains to be seen. The hors d'oeuvre promises well.

\section{E.E.P.}

\section{FLUID AND ELECTROLYTES IN PRACTICE}

By Harry Statland, M.D. Second Edition. Pp. Xv +229 , with 31 diagrams. London: Pitman Medical Pub. Co. Ltd. 1957. 45s.

The second edition of this well-balanced and lucid monograph for medical students follows closely the lines laid down in its predecessor, but as in the intervening period further considerable progress has been made in elucidating problems in this rapidly expanding field, the author has taken the advantage to incorporate certain new material within the general structure. For example, a new short section on hypernatraemia other than that due to dehydration has been included and the discussion on the acid-base disturbances has been expanded into a section of its own. The detailed management of acute renal failure has also been brought up to date and it is good to see that the volume of water produced by the metabolism of fat is incorporated in the calculation of fluid requirements in anuric patients, for all too often such patients are to be observed suffering slow but progressive dilution as a result of this factor being ignored.

The metabolic disturbances in acute salicylate poisoning are discussed in a new short section, the dangers of sodium bicarbonate therapy being emphasized, and numerous other small improvements are noticed. The author might consider for the next edition slight alterations to the diagrams of ionic changes in the acid-base disturbances, which some students find confusing, but these are a small blemish on a book which deserves continuing success.

B.J.H.
A MODERN PRACTICE OF OBSTETRICS

By D. M. Stern, M.A., M.B., B.Ch.(Cantab.), F.R.C.S., F.R.C.O.G., and C. W. F. BURNETT M.D.(Lond.), F.R.C.S , F.R.C.O.G. Second Edition. Pp. $x+258$, with 141 line drawings. London: Baillière, Tindall \& Cox. 1958. 45s.

A second edition of this book has now been called for, which means that it has proved popular.

It is strictly for the undergraduate, as even the most charitable reviewer must state that it is rather thin in places. It is adequate for the requirements of the qualifying examinations, but certainly not for any postgraduate study, except possibly for the diploma in obstetrics of the Royal College of Obstetricians and Gynaecologists.

Some of the ideas presented in it are oldfashioned and other ideas are definitely not in agreement with modern-day thought. For instance, the use of intrauterine paste is still mentioned, without any warning of its danger.

A most complicated operation for sterilization is described-or, rather, illustrated-and it is known that complicated operations give less good results than simple operations.

A claim is made to have written freshly about hypofibrinogenaemia, but this subject has really been dealt with in the most perfunctory way.

There are no illustrations, other than line draw ings, but these are excellently carried out.

The presentation of the book is beautiful and if certainly has its place among the undergraduate textbooks.

\section{BIOCHEMICAL INVESTIGATIONS IN DIAGNOSIS AND TREATMENT}

By John D. N. NabarRo, M.D., F.R.C.P. Second Edition. Pp. xi + 299. London: H. K. Lewis \& Co. Ltd. 1957. 25 s.

This deservedly popular book has now received its first revision, and although the author has made no major changes in its content, numerous small improvements have been made in the light of newer knowledge and several entirely new sections have been added, including an account of the now fashionable abnormal haemoglobins and a brief description of the biochemical findings in the malignant carcinoid syndrome.

The value of this book must surely lie in its approach to the subject matter. After several decades during which clinical chemistry has mostly been presented to the clinician as a bound volume of laboratory recipes, with notes on their usefulness or otherwise, the new vision of pathology as a dynamic system of specific biochemical disorders is refreshing, and this approach has been nicely adapted by the author to present current clinical and laboratory techniques as tools for systematic dissection of a biochemical system in ill patients. The actual laboratory manipulations are only described in outline, and the author concentrates attention on the 